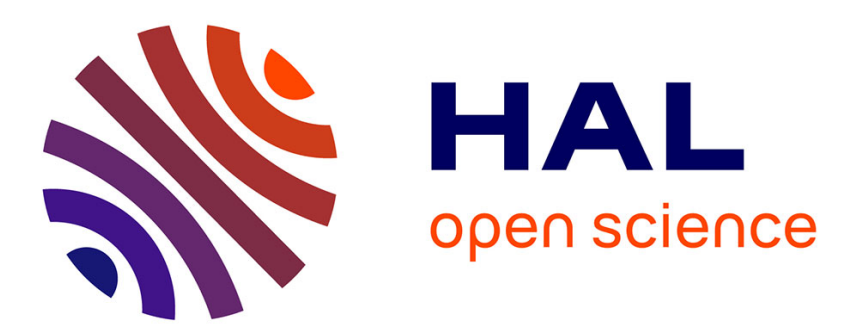

\title{
Energy use and Economic Growth in Africa: A Panel Granger-Causality Investigation
}

Mohamed El Hedi Arouri, Adel Ben Youssef, Hatem M'Henni, Christophe Rault

\section{- To cite this version:}

Mohamed El Hedi Arouri, Adel Ben Youssef, Hatem M'Henni, Christophe Rault. Energy use and Economic Growth in Africa: A Panel Granger-Causality Investigation. Economics Bulletin, 2014, 34 (2), pp.1247-1258. halshs-01068258

\section{HAL Id: halshs-01068258 \\ https://shs.hal.science/halshs-01068258}

Submitted on 30 Sep 2014

HAL is a multi-disciplinary open access archive for the deposit and dissemination of scientific research documents, whether they are published or not. The documents may come from teaching and research institutions in France or abroad, or from public or private research centers.
L'archive ouverte pluridisciplinaire HAL, est destinée au dépôt et à la diffusion de documents scientifiques de niveau recherche, publiés ou non, émanant des établissements d'enseignement et de recherche français ou étrangers, des laboratoires publics ou privés. 


\title{
Energy use and economic growth in Africa: a panel \\ Granger-causality investigation
}

\author{
Mohamed EI Hedi AROURI \\ EDHEC Business School \\ mohamed.arouri@edhec.edu \\ Adel BEN YOUSSEF \\ GREDEG-CNRS \& Université de Nice Sophia-Antipolis \\ adel.ben-youssef@unice.fr \\ Hatem M'HENNI \\ ESC Tunis, University of Manouba \\ hatem.mhenni@topnet.tn \\ Christophe RAULT \\ LEO, Université d'Orléans (UMR CNRS 7322), and Toulouse Business School, France \\ chrault@hotmail.com
}

\begin{abstract}
We make use of a bootstrap panel analysis of causality between energy use and economic growth for a sample of sixteen African countries over the period 1988-2010. Our results show that growth and energy use are strongly linked in Africa. However, African countries are heterogeneous and there is no "one way" recommendation about energy-growth relationship that may work for all countries in Africa.
\end{abstract}

JEL Classification: Q43, Q53, Q56

Keywords: Energy use, Growth, VAR 


\section{Introduction}

Last decade, Africa has experienced a rapid growth with on average 5\% yearly increase in GDP despite several international crises. Seven over the ten fastest growth rate economies in the world were in Africa. This rapid growth leads to a more interest paid to Africa and changes its reputation from a continent of civil wars, instability and famine to a continent of hope and business opportunities and development. In this paper, we hypothesize that one the key issues related to this rapid growth is energy and contribute to the literature by investigating the nature of the relationship between energy and economic growth in Africa. Indeed, the use of energy fosters economic opportunities; decreases travel costs and upgrade the industrial sector leading to a modernization of the economy (Poveda and Martinez, 2011). However, the consumption of the continent in matter of energy is still low compared to other regions. For instance, in 2009, electricity consumption in Europe was eleven fold the total consumption in Sub-Saharan Africa (SSA), in spite of SSA countries having a larger population (World Bank, 2011). Naturally, one can expect that Africa will increase strongly its energy consumption in the short- and mid-terms as its economy is modernizing, its urbanization is gaining and its demographic is changing. Hence, understanding the relationship between energy and economic growth in Africa becomes indispensable for both economists and policymakers.

Two channels, at least, explain how energy use can foster economic growth in Africa. Firstly, energy use is permitting greater human capital accumulation in Africa that leads to a rapid economic growth especially since 2000 . The economic literature has shown that energy use contribute to capital and labor productivity, promotes export potential of countries (Narayan and Smith, 2009), creates employment (Narayan and Smyth, 2005), decreases poverty level and improves socio-economic development (Poveda and Martinez, 2011). Generally, the empirical works show that the level of economic growth is positively correlated with the intensity of energy use. Second, Africa is expected to benefits from its demographic dividend (Bloom et al, 2007). UN (2011) stressed Africa is booming and there is a rapid change in its demographic. Its total population is expected to reach 2.3 billion in 2050 (while it is just 1 billion in 2010). Using this mass population in its productive sector will needs complementary inputs such as energy or infrastructures. Since then, as energy use is increasing Africa can harness its human capital and labor force in order to accelerate its economic growth.

Our paper proposes a bootstrap panel analysis of causality between energy use and economic growth for a sample of 16 African countries. Specifically, we first estimate a panel Vector AutoRegressive (VAR) model over the 1988-2010 period and then implement the panel-data approach of Kónya (2006), based on Seemingly Unrelated Regressions (SUR) system and Wald tests with country specific bootstrap critical values. In the specific framework we use, we allow for cross-country correlation, without the need of pretesting for unit roots and cointegration (as in Phillips, 1995). From an economic point of view, this means that we are able to test for Granger-causality between energy use and economic growth in a panel composed of 16 African countries, and to get country-specific results about the direction of causality. The paper shows that behind these general trends, the relationship between energy use and economic growth in Africa presents a strong heterogeneity and complexity. Based 
on our empirical findings, we highlight the limits of a number of "cooked" policy recommendations: Each African country is a special case and there is no unique and universal policy in matter of energy use in Africa.

The rest of the paper is organized as follows. Section 2 discusses the existing literature. Section 3 is devoted to the data and the panel Granger causality test methodology. Section 4 reports our empirical findings. Section 5 provides policy discussion and concluding remarks.

\section{Energy use and economic growth: Empirical Literature Review}

There is a large empirical literature exploring the role of energy in economic growth in the context of developing countries. While there is no consensus about the nature of the direction of the causality between energy use and economic growth, strong assumptions suppose that both the two sides of the relationships are valid: energy use leads to higher growth rate and growth leads to an increase in consumption of energy (Toman and Jemelkova, 2003; Arbex and Perobelli, 2010). This literature shows that the hypothesis of neutrality of energy use in classical model of growth is no more valid nowadays. In this short literature review we restrict ourselves to contribution focused on twelve SSA countries and four North African countries: Algeria, Egypt, Morocco and Tunisia.

The first strand of literature examines the existing of a feedback hypothesis between energy consumption and economic growth. Odhiambo (2009) investigates causality between economic growth and electricity consumption in the case of South Africa. The findings suggest a feedback link between the two variables. Similar findings are reached by Jumbe (2004), Adom (2011), Kouakou (2011) and Ouédraogo (2010) for Malawi, Côte d'Ivoire and Burkina Faso, respectively. Salarin and Shahbaz (2013) explore the causal relationship between economic growth, urbanization and electricity consumption in Angola by using the Granger causality. The authors show the existing of bidirectional causality between economic growth, urbanization and electricity consumption in the case of Angola for the period 1971-2009 in the long run. They conclude that Angola is energy-dependent country; the continuation of rapid growth in Angola is dependent of the capacity of the country to provide electricity for its economy in the near future. Solarin and Bello (2011) probed the electricity-growth nexus for the Nigerian economy by incorporating a capital and labor in the production function. They validated the presence of growth hypotheses, which suggests the need to exploration of new sources of energy to sustain economic growth.

Belaïd and Abderrahmani (2013) investigate the causality between electricity consumption, petroleum prices and economic growth for the Algerian economy. Their findings show a feedback effect between electricity consumption and economic growth. Finally, Esso (2010) investigates the causality relationship between energy consumption and economic growth for seven Sub-Saharan African countries during the period 19702007. Using the bounds testing approach to cointegration, he finds that energy consumption is cointegrated with economic growth in Cameroon, Congo, Côte d'Ivoire, and South Africa. Causality tests suggest bidirectional causality between energy consumption and real GDP in Côte d'Ivoire and unidirectional causality running from real GDP to energy usage in the case of Congo.

The second strand of literature focus on the demand functions of energy and find a positive relationship between income and energy demand. Adom et al. (2012) use 
an electricity demand function and apply the ADRL bounds testing to examine the relationship between electricity consumption and economic growth. Their results indicate that income, industrial growth and urbanization are contributing factors to electricity consumption in Ghana. Ubani (2013) uses a multiple linear regression approach in order to determine the determinants of the demand function in Nigeria. He found that urbanization, population density, number of manufacturing industry of households with electricity, employment rate and distance to nearest power generation station are significant determinants of the energy consumption in Nigeria between 1985 and 2005.

Our work contributes to this ongoing literature by addressing several questions. Indeed, the empirical literature on the link between economic growth and energy use or consumption in Africa, even if it is increasingly growing, is still low compared to other regions of the world. In addition, the results previous works lead are often contradictory and need to be confirmed by more recent econometric techniques. Moreover, most previous studies have chosen to work on energy consumption while we think that energy use is a more relevant variable because it better reflects the situation in African countries characterized by informal consumption of energy (and therefore unaccounted). ${ }^{1}$ Finally, the choice of the countries of our sample is itself interesting because all regions of Africa are represented. Hence the richness of the situations studied and evidence that the problems are not the same for each region or for each country and therefore the solution may not be the same for all countries.

\section{Data and the Econometric Methodology}

\subsection{Data}

We make use of data from World Development Indicators Database (World Bank, 2013). ${ }^{2}$ Given the purpose of our study, we extract the following variables: energy use and economic growth as well as a series of control variable related to both energy use and economic growth.

\subsection{Series specific panel Granger causality test methodology}

We use the panel data approach developed by Kónya (2006), based on a bivariate finiteorder vector autoregressive model, and we apply it in our context to energy use (E) and economic growth (GROWTH): ${ }^{3}$

\footnotetext{
${ }^{1}$ Energy use refers to use of primary energy before transformation to other end-use fuels, which is equal to indigenous production plus imports and stock changes, minus exports and fuels supplied to ships and aircraft engaged in international transport.

${ }^{2}$ Data are available at http://data.worldbank.org/.

${ }^{3}$ We are grateful to L. Kónya for providing his TSP codes, which we have adapted for our analysis.
} 


$$
\left\{\begin{array}{c}
E_{i t}=\alpha_{1 i}+\sum_{j=1}^{p_{1 i}} \beta_{1, i, j} E_{i t-j}+\sum_{j=1}^{p_{2, i}} \gamma_{1, i, j} G R O W T H_{i t-j}+\varepsilon_{1, i, t} \quad t=1, \ldots, T i=1, \ldots, N \quad(1 a) \\
G R O W T H_{i t}=\alpha_{1 i}+\sum_{j=1}^{p_{1 i}} \beta_{2, i, j} E_{i t-j}+\sum_{j=1}^{p_{2, i}} \gamma_{2, i, j} G R O W T H_{i t-j}+\varepsilon_{2, i, t} \quad t=1, \ldots, T i=1, \ldots, N
\end{array}\right.
$$

where the index $i(i=1, \ldots, N)$ denotes the country, the index $t(t=1, \ldots, T)$ the period, $j$ the lag, and $p_{1 i}, p_{2 i}$ and $p_{3 i}$, indicate the longest lags in the system. The error terms, $\varepsilon_{1, i, t}$ and $\varepsilon_{2, i, t}$, are supposed to be white-noises (i.e. they have zero means, constant variances and are individually serially uncorrelated) and may be correlated with each other for a given country, but not across countries.

System $(1 \mathrm{a}, 1 \mathrm{~b})$ is estimated by the Seemingly Unrelated Regressions (SUR) procedure, since possible links may exist among individual regressions via contemporaneous correlation ${ }^{4}$ within the two equations. Wald tests for Granger causality are performed with country specific bootstrap critical values generated by simulations.

With respect to system $(1 \mathrm{a}, 1 \mathrm{~b})$, in country $i$ there is one-way Granger-causality from GROWTH to $\mathrm{E}$ if in the first equation not all $\gamma_{1, i}$ are zero but in the second all $\beta_{2, i}$ are zero; there is one-way Granger-causality from E to GROWTH if in the first equation all $\gamma_{1, i}$ are zero but in the second not all $\beta_{2, i}$ are zero; there is two-way Grangercausality between E to GROWTH if neither all $\beta_{2, i}$ nor all $\gamma_{1, i}$ are zero; and there is no Granger-causality between E to GROWTH if all $\beta_{2, i}$ and $\gamma_{1, i}$ are zero. ${ }^{5}$

This procedure has several advantages. Firstly, it does not assume that the panel is homogenous, so it is possible to test for Granger-causality on each individual panel member separately. However, since contemporaneous correlation is allowed across countries, it makes it possible to exploit the extra information provided by the panel data setting and therefore country-specific bootstrap critical values are generated. Secondly, this panel approach which generalizes the methodology developed by Phillips $(1995)^{6}$ that tests for non-causality in levels VARs, in a time series context, does not also require pretesting for unit roots and cointegration, though it still requires the

\footnotetext{
${ }^{4}$ This assumption is very likely to be relevant for many macroeconomic time series for African countries for which strong economic links exist.

${ }^{5}$ As stressed by Kónya (2006) this definition implies causality for one period ahead.

${ }^{6}$ As it is now well known the issue of testing for non-causality is addressed in a time series setting, in particular by Phillips (1995) in the context of a VAR in levels estimated using the fully modified (FM) estimator, and also by Toda and Yamamoto (1995) who suggest augmenting the VAR by the maximal order of integration for the process being examined. The former method provides some very interesting results as far as asymptotic inference is concerned. The most important one is that statistical inference in this framework can be conducted by means of standard asymptotics; no unit root limit theory is required. Normal and mixed normal limit theory are applied to the stationary and non-stationary components of the VAR respectively. This implies that optimal inference in levels VARs and Wald test for non-causality can be obtained without prior knowledge of the number of unit roots or the order of cointegration rank in the system, and without the use of reduced rank Johansen-type regressions (which are subject to pre-testing bias, as tests for cointegration ranks are extremely sensitive to the values of the nuisance parameters). The approach by Toda and Yamamoto (1995) also results in a standard Wald statistic for non-causality restrictions, although it does require some pre-testing for determining the lag length of the VAR.
} 
specification of the lag structure (which is determined here using the Akaike Information Criterion (AIC) and the Schwarz Information Criterion (SIC)). This is an important feature since the unit-root and cointegration tests in general suffer from low power, and different tests often lead to contradictory outcomes. Thirdly, this panel Granger causality approach allows the researcher to detect for how many and for which members of the panel there exists one-way Granger-causality, two-way Grangercausality or no Granger-causality.

To sum up, from an economic point of view, the approach developed by Kónya (2006), allows us to test for Granger-causality between energy use and economic growth in a panel framework composed of African countries, and to get country-specific results about the direction of causality.

\section{Empirical findings}

Using the AIC and SIC criteria and a maximal lag parameters of 3, a VAR(1) model is found to describe adequately the dynamics of the series under consideration, the misspecification tests indicating no departure from the underlying assumptions. We then carry out the Breusch and Pagan (1980) test to investigate whether the variancecovariance matrix of the errors is diagonal, and the null hypothesis of no contemporaneous correlation within the different systems can always be rejected at the five percent significance level. This justifies the application of the SUR estimators which is here more efficient than the OLS estimators.

Tables 1a and $1 \mathrm{~b}$ show the results of the causality tests between energy use and growth for a sample of 16 African countries for the period 1988-2010. These results can be classified into four cases: (1) growth significantly affects energy use in Algeria, (2) a unidirectional causality from energy use to growth in Egypt, DRC, Kenya, Morocco, Senegal, Tanzania and Tunisia, (3) Energy use negatively causes GDP growth in Cameroon, South Africa and Zambia and (4) a bidirectional causality from energy use to growth and from growth to energy use in Ethiopia.

Table 1a - Granger causality tests from Economic growth to Energy use over the period 1988-2010, bivariate (ENERGY, GROWTH) model

\begin{tabular}{|c|c|c|c|c|c|}
\hline & \multirow{2}{*}{$\begin{array}{c}\text { Estimated } \\
\text { coefficient }\end{array}$} & \multirow[t]{2}{*}{ Test Statistic } & \multicolumn{3}{|c|}{ Bootstrap critical values } \\
\hline & & & $1 \%$ & $5 \%$ & $10 \%$ \\
\hline Algeria & 0.0842 & $9.6947 * *$ & 15.6348 & 9.4698 & 7.8800 \\
\hline Benin & 0.0583 & 2.0403 & 15.7348 & 11.3699 & 8.7598 \\
\hline Cameroon & -0.0153 & -2.9245 & 23.5039 & 14.6592 & 8.8493 \\
\hline Democratic Republic of Congo & -0.0225 & -2.4214 & 18.0007 & 13.2285 & 10.2840 \\
\hline Egypt & 0.0261 & 1.6023 & 32.1570 & 23.4312 & 18.7012 \\
\hline Ethiopia & 0.2348 & $9.4222 * *$ & 17.8128 & 8.1742 & 6.4418 \\
\hline Ghana & -0.0122 & -.99519 & 6.9771 & 5.2008 & 4.1138 \\
\hline Kenya & 0.0058 & .17229 & 17.3195 & 13.1589 & 10.0292 \\
\hline Morocco & 0.0431 & 5.2613 & 23.2874 & 16.6316 & 12.7436 \\
\hline Mozambique & 0.0375 & 5.0057 & 21.0201 & 17.4546 & 14.7753 \\
\hline Nigeria & -0.0086 & -.77335 & 2.9828 & 2.2818 & 1.8027 \\
\hline Senegal & 0.0560 & 3.2909 & 12.6507 & 9.6764 & 7.6103 \\
\hline South Africa & 0.1384 & 3.7352 & 4.4251 & 3.5061 & 2.7754 \\
\hline Tanzania & -0.0264 & -1.6241 & 23.7736 & 17.6046 & 13.8006 \\
\hline Tunisia & 0.0332 & 2.3216 & 11.0254 & 8.1876 & 6.2813 \\
\hline Zambia & 0.0394 & 2.9647 & 23.3549 & 18.0434 & 14.7581 \\
\hline
\end{tabular}


Table $1 \mathrm{~b}$ - Granger causality tests from Energy use to Economic growth over the period 1988-2010, bivariate (ENERGY, GROWTH) model

\begin{tabular}{lrcccc}
\hline \hline & Estimated & Test Statistic & \multicolumn{3}{c}{ Bootstrap critical values } \\
\cline { 4 - 6 } & coefficient & & \multicolumn{1}{c}{$5 \%$} & $10 \%$ \\
\hline Algeria & 0.3480 & .97691 & 22.9350 & 17.0466 & 13.2541 \\
Benin & -0.0478 & -.61550 & 22.6867 & 16.3327 & 13.0056 \\
Cameroon & -1.3085 & $-4.1581^{*}$ & 8.5811 & 6.3249 & 3.9351 \\
Democratic Republic of Congo & 0.3701 & $6.4577^{*}$ & 16.6605 & 8.4513 & 4.8030 \\
Egypt & 0.7059 & $11.542^{* *}$ & 20.9908 & 11.3714 & 8.7930 \\
Ethiopia & -0.7234 & $-17.252^{* *}$ & 21.9534 & 16.3646 & 12.6536 \\
Ghana & -0.1079 & -1.0242 & 39.5181 & 31.3425 & 25.6793 \\
Kenya & 4.1158 & $15.421^{* * *}$ & 22.7700 & 13.7982 & 7.8448 \\
Morocco & 4.1698 & $5.9188^{*}$ & 16.4594 & 8.1568 & 4.3522 \\
Mozambique & -0.1184 & -1.1280 & 15.1987 & 11.3459 & 8.7555 \\
Nigeria & 0.2749 & 1.0487 & 28.0388 & 20.3604 & 16.3365 \\
Senegal & 1.3015 & $3.94631^{*}$ & 12.7679 & 5.3671 & 2.8787 \\
South Africa & -0.6853 & $-5.3770^{*}$ & 14.2091 & 7.2279 & 4.6973 \\
Tanzania & 0.5826 & $6.3629 *$ & 17.5726 & 9.0588 & 5.1250 \\
Tunisia & 1.1614 & $3.8931^{*}$ & 19.3766 & 6.8340 & 3.5142 \\
Zambia & -0.7684 & $-3.3582^{*}$ & 22.1460 & 10.7384 & 3.0545 \\
\hline \hline
\end{tabular}

We now discuss in more details these four cases.

\section{(1) GDP positively causes energy use}

Economic growth causes energy use in Algeria. This is a special case in our panel. Algeria is among the largest producers of energy (oil and gas) in Africa. The expansion of GDP is mainly caused by the expansion of the production of energy. As energy production (prices or quantity), the total revenue increase causing the increase of the income per capita which leads to an increase of energy use and economic growth. Since that, the domestic revenue increases leading to an increase of the domestic consumption and the energy use (domestic use of energy). We need to mention that the reverse causality is not verified for the case of Algeria. Our results do not confirm the findings of Belaïd and Abderrahmani (2013) who find bidirectional causality for Algeria. Their work was based on electricity consumption and not all energy use.

\section{(2) Energy use positively causes GDP growth}


In most of the panel considered (Egypt, DRC, Kenya, Morocco, Senegal, Tanzania and Tunisia), energy use positively causes economic growth. This positive impact suggests that an increase in energy use increases the GDP. This is found in most of the literature, Arbex and Perobelli (2010) and references therein. The novelty is that this link is not depending on the level of development of the country: DRC is a Fragile State, Senegal and Kenya are countries in development, Tunisia and Morocco can be considered as middle Income Countries. The finding is also valid in all African regions (North, South, East and West). Economic growth is linked to the use and consumption of energy in those countries. Those countries are expanding the electricity coverage and electrification allows better opportunities for work, for training and varieties of economic activities. At the same time, those countries are expanding their urbanization allowing more availability of transport. Those activities are energy consuming and allowing better economic growth. Energy use also allows these countries to increase their usage of information and communication technologies (ICT) and to benefit more from the digital world. Moreover, by the increase of energy use the economic capacity of exportation of the country increases (Eggoh et al. 2011).

\section{(3) Energy use negatively causes GDP growth}

This is an unexpected result found for three countries: Cameroon, South Africa and Zambia). The negative impact of energy use on economic growth may be explained by the fact that those countries are mainly net importers of energy. In order to satisfy their increasing needs of energy these countries import it.

As in most Sub-Saharan African countries, in Cameroon wood is the most widely used form of energy. Biomass covers $63 \%$ of overall consumption and more than $90 \%$ of the needs of the residential and tertiary sectors. The long-term electricity sector development plan (up to 2030: PDSE-2030) was launched in 2007. Its main strategic axes are the development of new production capacities, mainly from hydro, in order to tackle the electricity supply deficit; the modernisation and development of the grid. Oil production is falling slowly: in 2011 it was $3.1 \mathrm{Mt}$, which is far below its 1984 peak level of $8.8 \mathrm{Mt}$. In 2012, production increased by 5\% thanks to the optimisation of production at Rio Del Rey and the resumption of production at existing wells (Rio Del Rey and Mokoko Abana).

Over the past decade, Zambia's economy has grown at an average of 5 percent per annum, and this has seen an increased demand for energy too. Demand for electricity has grown at an average of about 3 percent per annum largely due to the increased economic activity in the country, particularly in the agriculture, manufacturing, and mining sectors.

EIA estimates show that South Africa's total electricity consumption grew by 20 percent from 2000 to 2010, while installed capacity grew at a slower rate of 7 percent during that same time period. In late 2007 and early 2008, as a result of high economic growth and growing electricity demand, and in the absence of any new power plants, the country experienced a power crisis that resulted in several blackouts and threatened the power supply to many businesses, including the mining industry. Gold, diamond, platinum, and coal producers had to temporally shut down underground mining activities for nearly a week since the national Company could not guarantee electricity supplies. The country also had to ration its electricity exports to neighboring countries. 


\section{(4) Bidirectional causality between energy use and GDP}

Ethiopia is a special case where bidirectional causality is observed. GDP causes energy use positively, while energy use is causing negatively economic growth. Ethiopia as one of the most populated countries in Africa with more than 80 million inhabitants has strong needs in matter of energy. The country is net importer of energy but it is trying to diversify its sources of energy by using renewable energies (hydraulics, wind, solar...). The largest wind farm in the world was implanted in Ethiopia recently. The construction of the hydropower on the Nile is another big project showing how Ethiopian authorities are taking this issue seriously. In the short-term however, importation of energy harms GDP growth. We may also notice that Ethiopia is also one of the less urbanized countries in Africa. Expanding energy access to own citizens implies strong budget efforts that may cause negative impacts in the short-run for its growth. Despite the fact that energy use is impacting negatively the GDP, Ethiopia is one of the most fast growing Economies in Africa.

\section{Policy discussion and concluding remarks}

We used a bootstrap panel analysis of causality between energy use and economic growth for a sample of 16 African countries, which is based on SUR systems and Wald tests with country-specific bootstrap critical values allowing for contemporaneous correlation across countries. The results support that the causality between economic growth and energy use nexus is not depending on the stage of development of the country in Africa as suggested by Poumanyvong and Kaneko (2010). Energy endowments, urbanization, Demographics and economic policies and may explain these differences in the causality between economic growth and energy use.

Our paper shows that four different situations are found: (1) growth significantly affects energy, (2) a bidirectional causality from energy to growth and from growth to energy in Ethiopia, (3) Energy use negatively causes GDP growth and (4) Bidirectional causality between energy use and GDP. Our findings suggest that public policies need to be customized and there is no "one way" of recommendations about energy consumption in Africa.

Dramatic shortages in countries like Nigeria or Ethiopia of electricity are harming the diversification of their economy and to reach higher economic growth. As an example, while Nigeria is belonging to the G20 and is expecting to play a prominent role at the international area in the future, it faces dramatic problems in matter of Electricity supply.

Africa can benefit from natural resources (oceans, deserts, forests...) to improve and diversify its sources of energy. This will require to construct and upgrade its capacity absorption of modern technologies and to spend more on R\&D in this particular area. Africa has weak research capacity in general and especially in matter of energy sector. Strengthening this capacity and build skills in matter of research and development are key for the full exploitation of its potential. The potential of solar energy in the continent is huge. Building the required skills for this sector permits to increase the energy supply and creates new jobs in the region. 


\section{References}

- Adom P. K. (2011), Electricity consumption-economic growth nexus: The Ghanaian case. International Journal of Energy Economics and Policy 1, 18-31.

- Adom P.K., Bekoe W., Akoena SKK. (2012), Modelling aggregate domestic electricity demand in Ghana: An autoregressive distributed lag bounds cointegration approach. Energy Policy, 42, 530-537.

- Arbex, M. and F.S. Perobelli (2010), Solow meets Leontief: Economic growth and energy consumption. Energy Economics 43, 43-53.

- Bélaïd, F., Abderrahmani, F., (2013). Electricity consumption and economic growth in Algeria: A multivariate causality analysis in the presence of structural change. Energy Policy, 55, 286-295.

- Bloom D.E., Canning, D., Fink, G. \& Finlay, J. (2007). Realizing the Demographic Dividend: Is Africa any different? Cambridge, MA: Harvard University, Program on the Global Demography of Aging.

- Breusch, T., and Pagan, A. (1980). The Lagrange multiplier test and its applications to model speci.cation in econometrics. The Review of Economic Studies, 47(1): 239.253.

- Eggoh J.C., Bangake Ch. And Ch. Rault (2011), Energy Consumption and Economic Growth Revisited in African Countries, Energy Policy, 39, 7408-7421.

- Esso, L.J., 2010. Threshold cointegration and causality relationship between energy use and growth in seven African countries. Energy Economics 32, 1383-1391.

- Jumbe, C. (2004) Cointegration and causality between electricity consumption and GDP: empirical evidence from Malawi. Energy Economics, 26, 61-68.

- Kónya, L. (2006), "Exports and growth: Granger causality analysis on OECD countries with a panel data approach", Economic Modelling, 23, 978-982.

- Kouakou, A., (2011), Economic growth and electricity consumption in Cote d'Ivoire: Evidence from time series analysis. Energy Policy 39, 3638-3644

- Narayan, P.K., and Smyth, R. (2009), "Multivariate Granger causality between electricity consumption, exports and GDP: evidence from a panel of Middle Eastern countries". Energy Policy, 37, 229-236.

- Narayan, P.K., and Smyth, R. (2005), "Electricity consumption, employment and real income in Australia evidence from multivariate Granger causality tests". Energy Policy, 33, 1109-1116.

- Odhiambo, N., (2009), Electricity consumption and economic growth in South Africa: A trivariate causality test. Energy Economics 31, 635-640.

- Ouédraogo, I., 2010. Electricity consumption and economic growth in Burkina Faso: A cointegration analysis. Energy Economics 32, 524-531.

- Phillips, P.C.B. (1995), "Fully Modified Least Squares and Vector Autoregression", Econometrica, vol 63, 5, pp 1023-1078.

- Poveda, A., Martínez, C., 2011. Trends in economic growth, poverty and energy in Colombia: long-run and short-run effects. Energy System, 2, 281-298.

- Poumanyvoung, P., and Kaneko, S. (2010), "Does Urbanization lead to less energy use and lower CO2 emissions? A cross-country analysis" Ecological Economics, 70 (2010), 434-444.

- Solarin S., Shahbaz M. (2013), Trivariate Causality between Economic Growth, Urbanisation and Electricity Consumption in Angola: Cointegration and Causality Analysis. MPRA Paper No. 45580

- Solarin, S., Bello, M., (2011), Multivariate causality test on electricity consumption, capital, labour and economic growth for Nigeria. Journal of Business and Economics $3,1-29$. 
- Toda, H. Y. and Yamamoto, T. (1995), "Statistical inference in vector autoregressions with possibly integrated processes". Journal of Econometrics, 66, $225-250$.

- Toman, T. and B. Jemelkova (2003) Energy and economic development: An assessment of the state of knowledge. Energy Journal, 24, 93-112.

- Ubani, O. (2013), Determinants of the dynamics of electricity consumption in Nigeria, OPEC Energy Review,

- United Nations. (2011). World Population Prospects: The 2010 Revision. New York, NY: United Nations, Department of Economic and Social Affairs, Population Division.

- World Bank (2011), World Development Indicators on CD-ROM, Washington, DC. 